\title{
VIBRATIONAL CASE STUDY FOR THE MOLD OSCILLATOR WITH HYDRAULIC SERVO SYSTEM
}

\author{
YONGHUI PARK ${ }^{* 1}$, CHANGWOO LEE ${ }^{2,3}$, DONGWOOK KIM ${ }^{2,3}$ \\ ${ }^{1}$ Department of Mechanical Engineering Mechanical System Major, Yuhan University, \\ 590 Gyeongin-ro, Sosa-gu, Bucheon-si, Republic of Korea \\ ${ }^{2}$ Advanced Fusion Technology Research Division, Pohang Institute of Metal Industry \\ Advancement, 56 Jigok-ro Nam-gu, Pohang-si, Gyeongsangbuk-do, Republic of Korea \\ ${ }^{3}$ Department of Mechanical Engineering, Pohang University of Science and Technology, \\ 77 Cheongam-ro Nam-gu, Pohang-si, Gyeongsangbuk-do, Republic of Korea
}

\begin{abstract}
We have conducted sensitivity analysis to investigate the two-hydraulic-servo system for the mold oscillator. By modelling mathematical models for operating fluid flow to control a hydraulic cylinder, we changed design parameters and environment conditions including friction, additional spring stiffness and fluid leakage. From the one-hydraulic servo system to the two-hydraulic cylinder, modal analysis was conducted to figure out dynamic characteristics of the real system. Especially, we categorized important natural mode shape. When the system was excited into the natural frequency, the 1st mechanical natural frequency could cause a pressure gain by reducing internal pressure of a hydraulic cylinder, but other natural frequencies were critically dangerous by generating imbalance, over-vibration and distortion. By comparing the results to the experimental data, we could find a dramatic pressure drop near $3 \mathrm{~Hz}$ oscillation when the system has the 1 st mechanical natural frequency $2.499 \mathrm{~Hz}$. Also, the system has the imbalance near $6 \mathrm{~Hz}$ oscillation when the system has 2nd mechanical natural frequency $5.446 \mathrm{~Hz}$. Based on these fact, we have suggested some tips to oscillate a mold efficiently and safely.
\end{abstract}

Keywords: hydraulic servo system, mathematical model, natural frequency and mode, dynamic characteristics, structural disequilibrium.

\section{INTRODUCTION}

Electro-hydraulic servo systems (EHSSs) are used for precision motion control in industry. An EHSS consists of a controller, a servo valve system, a pump system, and a hydraulic cylinder, and has high efficiency compared to power input. However, the EHSS is complicated, has a leakage problem, and is difficult to maintain [1-5].

To compensate for these defects, numerous researches including a model of the electro-hydraulic servo system [6-9], dynamic response according operating fluid [10-11], robust controller [12], and guidelines for basic design [13-16] have been presented. Their research field is too wide to be arranged.

\footnotetext{
* Corresponding author, email yhpark@yuhan.ac.kr

(C) 2019 Alma Mater Publishing House
} 
The EHSS for a mold oscillator should oscillate a heavy mold consistently to minimize a generation of the mold oscillation mark. EHSSs are affected by factors such as relative motion between a mold and ingot, and the type of lubricating oil critically [17]. These effects are nonlinear and therefore cannot be modeled easily.

To maintain an optimal operation, analysis of sensitivity to changes to design variables and to oscillating conditions should be conducted by establishing an equivalent model before planning an operating condition that uses a hydraulic servo in industry [18-20]. However, in real operations the operator still selects an operating condition based on experimental engineering techniques, and runs the system using guidelines suggested by the manufacturer.

Problems always occur when an engineer changes a system design or structural design to improve performance without understanding the basic design. Although structural design of a mold; mechanical part including a rubber spring, coil spring, and guide roller does not predominate to the hydraulic servo system, an engineering problem must be defined properly and the process established before it can be optimized.

We investigate how several factors affect the dynamic characteristic of a mold oscillating mechanism. To understand basic mechanism, the model includes 1-degree-of-freedom (DoF) that include a hydraulic servo system, mass, damper, and spring system, and 2-DoF system is investigated about natural mode frequency and imbalance problem. Especially, the 2-DoF system is not considered in previous research, so the paper can give a suggestion for basic design. Because internal pressure of a hydraulic cylinder is determined by initial pressure and entrance flow of hydraulic oil, we include or do not include entrance flow information about an additional spring stiffness, friction, and leakage in the model and use the difference in results to check how entrance flow estimation affects the dynamic characteristics of the system.

The change is a design variable except basic design of the hydraulic cylinder. We use simulation to obtained distributions of displacement, velocity, acceleration, and pressure, convert time-domain data to frequencydomain data, and perform case studies to evaluate the effects of changing parameters.

\section{SYSTEM MODELING}

\subsection{Pressure model by entrance flow of the hydraulic oil}

The operating mechanism of the hydraulic servo system consists of a servo control system, a supplying and returning pump system, a servo valve system, a hydraulic cylinder, a mold system, and a feedback control system. Flow of hydraulic oil into the hydraulic cylinder is determined by difference between a current dynamic behavior and target dynamic behavior.

If the entrance flow of the hydraulic oil is defined, the oscillating mechanisms can be simplified to represent only the hydraulic cylinder and mold (Figure 1). Each parameter will be explained Table. 2 and Table. 3. These components can be represented by the continuity equation (Equation (1)) and force equilibrium (Equation (2)).

The continuity includes the flow of the hydraulic oil into the hydraulic cylinder, and can be derived by exploiting mass conservation: the entrance flow of the hydraulic oil equals the volume change of the hydraulic oil caused by piston motion, leakage, and compressibility.

$$
\begin{gathered}
Q_{A}=-A \dot{z}+\frac{\left(V_{0}-A z\right)}{\beta} \frac{d P_{A}}{d t}+C_{\mathrm{int}}\left(P_{A}-P_{B}\right)+C_{e x t} P_{A} \\
Q_{B}=A \dot{z}+\frac{\left(V_{0}+A z\right)}{\beta} \frac{d P_{B}}{d t}+C_{\mathrm{int}}\left(P_{B}-P_{A}\right)+C_{e x t} P_{B} \\
m \ddot{z}+c \dot{z}+k z=\left(P_{B}-P_{A}\right) A-m g-F_{\text {fric }}
\end{gathered}
$$

Based on equations (1) and (2), we wrote MATLAB code to calculate the entrance flow of the hydraulic oil when design variables and pressure in the chamber A are defined. Using the relationship (Figure 2) between the 
flow entrance and numerical analysis, we can modify additional spring stiffness, damping ratio, friction, and leakage easily.

By using a pre-defined equation of the pressure and displacement, we can get a high-order time derivative term, which we then use to represent the dynamic behavior and to derive the entrance flow and its higher order time derivative terms. Given the displacement and pressure and their time derivatives in step i-1, we can calculate the entrance flow and its time derivatives in step i-1, and the pressure and its time derivatives in step i (equation (3)):

$$
\begin{gathered}
\left\{\begin{array}{c}
\left.P_{A, i-1}, P_{B, i-1}, \dot{P}_{A, i-1}, \dot{P}_{B, i-1}, \ddot{P}_{A, i-1}, \ddot{P}_{B, i-1}, \cdots, \frac{d^{n} P_{A, i-1}}{d t^{n}}, \frac{d^{n} P_{B, i-1}}{d t^{n}}\right\} \\
\left.z_{i-1}, \dot{z}_{i-1}, \ddot{z}_{i-1}, \cdots, \frac{d^{n} z_{i-1}}{d t^{n}}\right\} \\
\stackrel{\begin{array}{c}
\text { Volume flow \& derivative } \\
\text { (pre-defined })
\end{array}}{\longrightarrow}\left\{Q_{A, i-1}, Q_{B, i-1}, \dot{Q}_{A, i-1}, \dot{Q}_{B, i-1}, \ddot{Q}_{A, i-1}, \ddot{Q}_{B, i-1}, \cdots, \frac{d^{n} Q_{A, i-1}}{d t^{n}}, \frac{d^{n} Q_{B, i-1}}{d t^{n}}\right\} \\
P_{A, i}=f\left(P_{A, i-1}, \dot{P}_{A, i-1}, \ddot{P}_{A, i-1}, \cdots, \frac{d^{n} P_{A, i-1}}{d t^{n}}, Q_{A, i-1}, \dot{Q}_{A, i-1}, \ddot{Q}_{A, i-1}, \cdots, \frac{d^{n} Q_{A, i-1}}{d t^{n}}\right) \\
P_{B, i}=f\left(P_{B, i-1}, \dot{P}_{B, i-1}, \ddot{P}_{B, i-1}, \cdots, \frac{d^{n} P_{B, i-1}}{d t^{n}}, Q_{B, i-1}, \dot{Q}_{B, i-1}, \ddot{Q}_{B, i-1}, \cdots, \frac{d^{n} Q_{B, i-1}}{d t^{n}}\right)
\end{array}\right\}
\end{gathered}
$$

\subsection{Mass-damper-spring system with one hydraulic servo system}

The hydraulic servo system executes one-directional back-and-forth motion. The oscillator can have several hydraulic servo systems in symmetric positions. Even though the hydraulic servo system is designed to oscillate the mold horizontally, design asymmetry may occur during the assembly process.

Due to this asymmetry, each hydraulic servo system applies different driving forces to the mold oscillator. Before investigating a mass-damper-spring system with two hydraulic servo systems (Next section), we check a mass-damper-spring system with one hydraulic servo system.

The equation of motion can be obtained from the pre-defined entrance flow (equation (5)). When the oscillating signal is defined, the entrance flow can be calculated, but the pressure in the cylinder chamber must be recalculated in every iteration, so we use the Taylor series to acquire the pressure in the current step from the pressure in the previous step. The pressure is applied to the equation of motion as an external force.

$$
\begin{aligned}
& Q_{A, i-1}, Q_{B, i-1}, \dot{Q}_{A, i-1}, \dot{Q}_{B, i-1}, \ddot{Q}_{A, i-1}, \ddot{Q}_{B, i-1}, \cdots, \frac{d^{n} Q_{A}}{d t^{n}}, \frac{d^{n} Q_{B}}{d t^{n}} \\
& \rightarrow P_{A, i-1}, P_{B, i-1}, \dot{P}_{A, i-1}, \dot{P}_{B, i-1}, \ddot{P}_{A, i-1}, \ddot{P}_{B, i-1} \cdots \frac{d^{n} P_{A, i-1}}{d t^{n}}, \frac{d^{n} P_{B, i-1}}{d t^{n}} \\
& \stackrel{\text { Numerical analysis }}{\longrightarrow} P_{A, i}, P_{B, i} \\
& \stackrel{\text { Exciting force }}{\longrightarrow} m \ddot{z}_{i}+c \dot{z}_{i}+k z_{i}=\left(P_{B, i}-P_{A, i}\right) A-m g-F_{\text {fric }}
\end{aligned}
$$

\subsection{Mass-damper-spring system with one hydraulic servo system}

A mold oscillator generally has two hydraulic servo systems mounted symmetrically at the end of the major axis. The model has 2 DoF: longitudinal z, and rotational $\theta$ (Figure 1): 
$Q_{A, i-1}, Q_{B, i-1}, \dot{Q}_{A, i-1}, \dot{Q}_{B, i-1}, \ddot{Q}_{A, i-1}, \ddot{Q}_{B, i-1}, \cdots, \frac{d^{n} Q_{A}}{d t^{n}}, \frac{d^{n} Q_{B}}{d t^{n}} \longrightarrow P_{A, i-1}, P_{B, i-1}, \dot{P}_{A, i-1}, \dot{P}_{B, i-1}, \ddot{P}_{A, i-1}, \ddot{P}_{B, i-1} \cdots \frac{d^{n} P_{A, i-1}}{d t^{n}}, \frac{d^{n} P_{B, i-1}}{d t^{n}}$

$\stackrel{\text { Numerical analysis }}{\longrightarrow} P_{\text {left_A }, i}, P_{\text {lef__B,i}}, P_{\text {right_A,i }}, P_{\text {right_B,i }}$

$\stackrel{\text { Exciting force }}{\longrightarrow}$

$\left[\begin{array}{cc}m & 0 \\ 0 & J\end{array}\right]\left\{\begin{array}{l}\ddot{z} \\ \ddot{\theta}\end{array}\right\}+\left[\begin{array}{cc}c_{s 1}+c_{s 2} & -c_{s 1} \times l_{s 1}+c_{s 2} \times l_{s 2} \\ -c_{s 1} \times l_{s 1}+c_{s 2} \times l_{s 2} & c_{s 1} \times l_{s 1}{ }^{2}+c_{s 2} \times l_{s 2}{ }^{2}\end{array}\right]\left\{\begin{array}{l}\dot{z} \\ \dot{\theta}\end{array}\right\}+\left[\begin{array}{cc}k_{s 1}+k_{s 2} & -k_{s 1} \times l_{s 1}+k_{s 2} \times l_{s 2} \\ -k_{s 1} \times l_{s 1}+k_{s 2} \times l_{s 2} & k_{s 1} \times l_{s 1}{ }^{2}+k_{s 2} \times l_{s 2}{ }^{2}\end{array}\right]\left\{\begin{array}{l}z \\ \theta\end{array}\right\}$

$$
=\left\{\begin{array}{c}
\left(P_{\text {left_B,i}}-P_{\text {left_A,i }}\right) \times A+\left(P_{\text {right_B,i}}-P_{\text {right_A,i }}\right) \times A-m g \\
-\left(P_{\text {left_B,i}}-P_{\text {left_A,i }}\right) \times A \times l_{h 1}+\left(P_{\text {right_B } B, i}-P_{\text {right } A, i}\right) \times A \times l_{h 2}
\end{array}\right\}
$$

The simulation is the same as in section 2.1, but the hydraulic servo system cannot detect a geometrical correlation between the hydraulic cylinder and spring stiffness, because each hydraulic servo system is only designed to one directional motion. The dynamic response varies according to factors including the geometric factor of spring stiffness, and spring position.
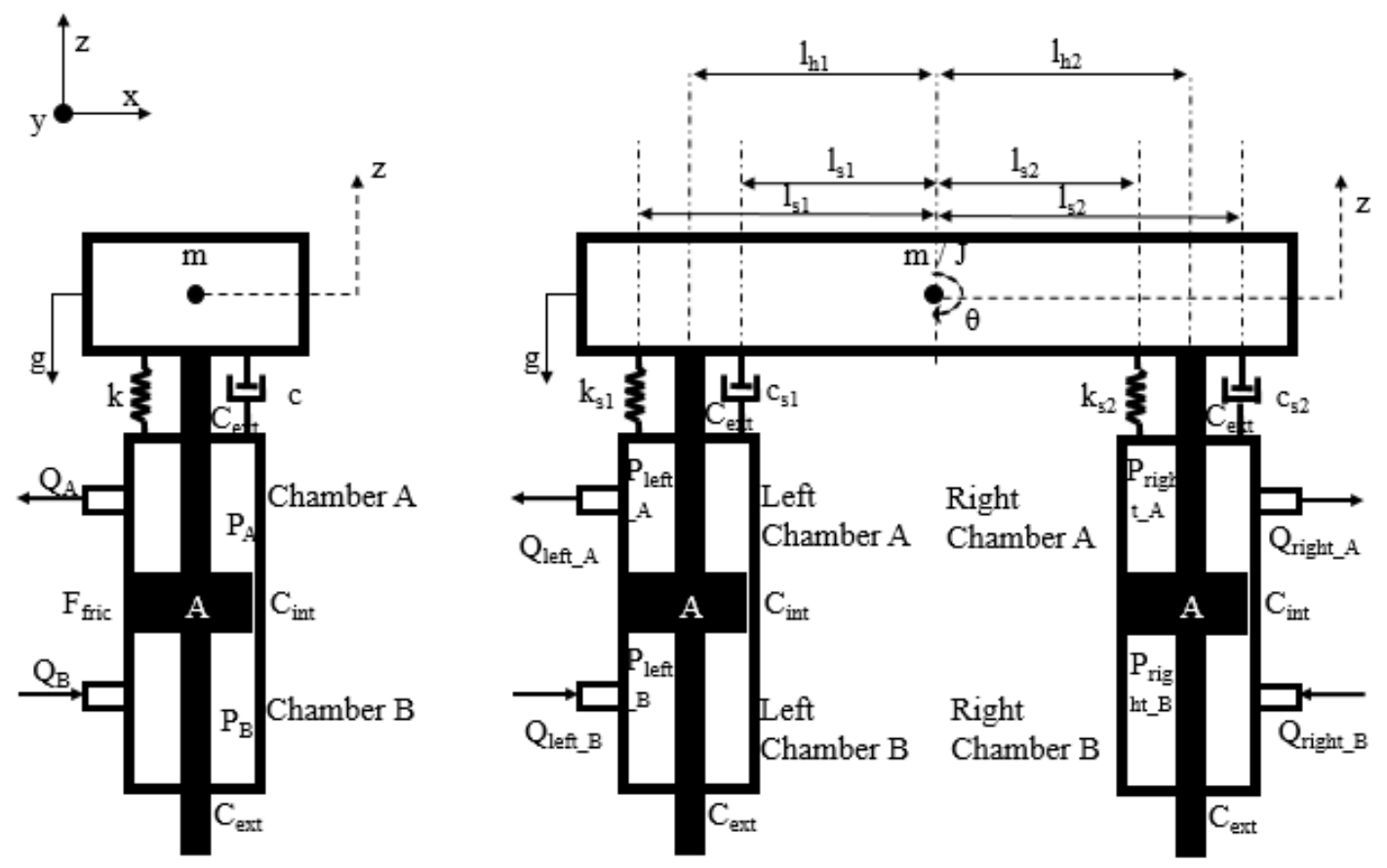

Fig. 1. Hydraulic cylinder and mass system with 1 supporting or 2 supporting type. 


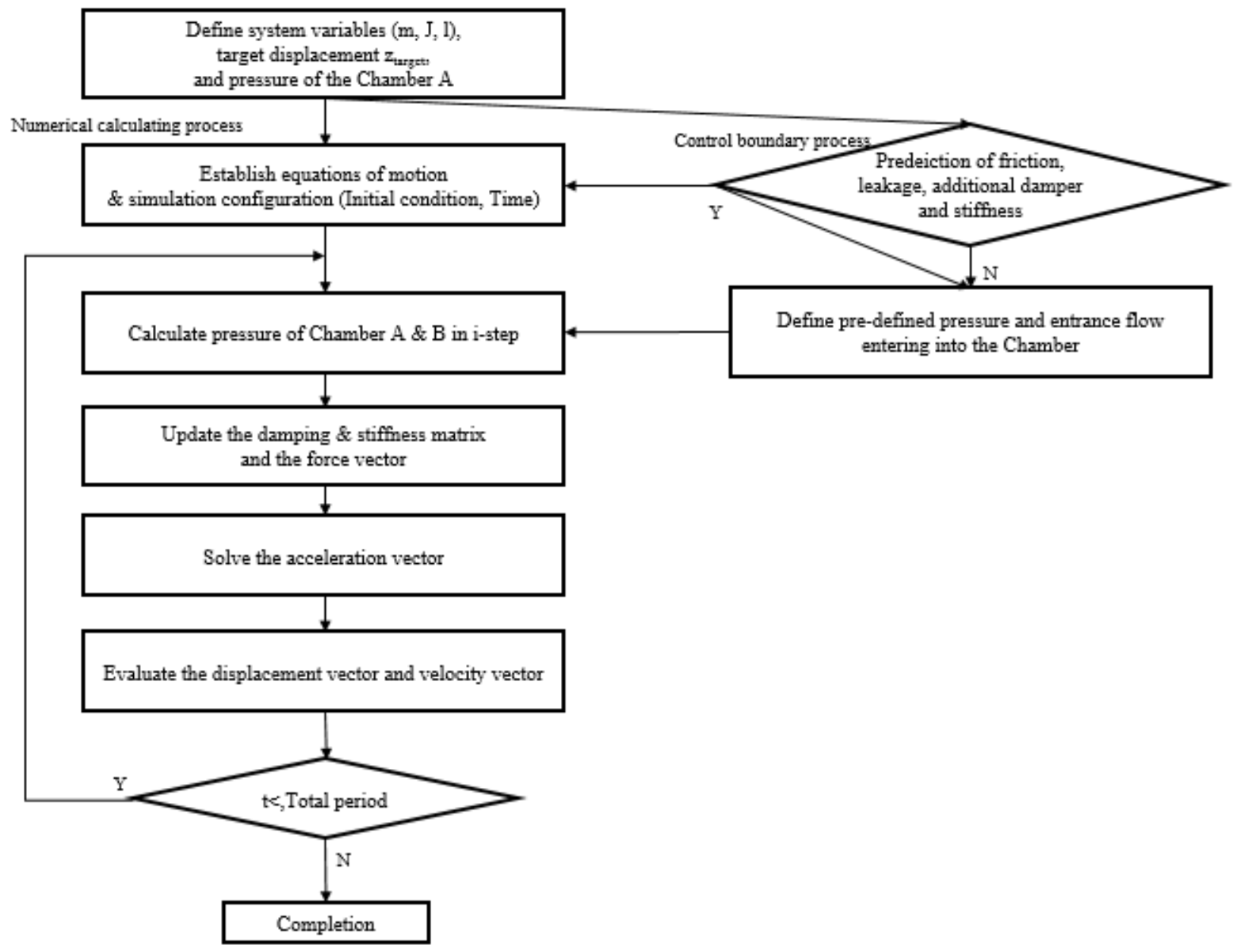

Fig. 2. Flow chart of the hydraulic inlet and outlet flow and numerical analysis.

\section{SIMULATION CONDITIONS}

3.1. Natural characteristic of the mass-damper-spring system with one hydraulic servo system and dynamic characteristic variation according to design variables

Without geometrical variables including a distance between the left and right spring, we investigate the relationships among the mechanical natural frequency, integrated natural frequency of the hydraulic and mechanical part, and oscillating condition by using the 1-DoF system. equation (6) is an integrated natural frequency that combines the hydraulic and mechanical natural frequencies.

$$
\omega_{h}=\sqrt{\left(\frac{4 \times \beta \times A^{2}}{V_{t}}+k\right) \frac{1}{m}}
$$

Simulations were conducted according to design variables (Table 1), for fixed and variable design parameters (Table 2). The variable design variable represents control accuracy. To locate the integrated natural frequency near the operating condition, we exaggerate the hydraulic cylinder length value to $5 \times 10^{4} \mathrm{~m}$. Entrance flows $\mathrm{Q}_{\mathrm{A}}$ and $\mathrm{Q}_{\mathrm{B}}$ were applied in every numeric integration after determining the pre-defined displacement and pressure.

Table 1. Design parameters simulated in the 1-DoF system.

\begin{tabular}{|c|c|}
\hline Case & Variable \\
\hline 1 & $k$ \\
\hline 2 & Friction \\
\hline 3 & Leakage \\
\hline
\end{tabular}


Table 2. System specifications and simulation conditions.

\begin{tabular}{|c|c|c|}
\hline & Quantity & Value \\
\hline \multirow{4}{*}{$\begin{array}{c}\text { Fixed } \\
\text { design } \\
\text { parameter }\end{array}$} & $m:$ Mass & $10 \mathrm{~kg}$ \\
\hline & $g$ : gravitational acceleration & $9.81 \mathrm{~m} / \mathrm{s}^{2}$ \\
\hline & $r_{i} / r_{o}:$ Inner / outer radius of the hydraulic cylinder & $0.2 / 1 \mathrm{~m}$ \\
\hline & $\beta:$ Bulk modulus & $1.7237 \times 10^{9} \mathrm{~N} / \mathrm{m}^{2}$ \\
\hline \multirow{5}{*}{$\begin{array}{l}\text { Variable } \\
\text { design } \\
\text { parameter }\end{array}$} & $k:$ spring stiffness & $k[\mathrm{~N} / \mathrm{m}]$ \\
\hline & $c:$ damping coefficient & $c[\mathrm{~N} /(\mathrm{m} \cdot \mathrm{s})]$ \\
\hline & $C_{\text {in }} / C_{\text {out }}:$ Internal/External leakage coefficient & $C_{\text {in }} / C_{\text {out }}\left[\mathrm{m}^{5} /(\mathrm{N} \cdot \mathrm{s})\right]$ \\
\hline & $F_{\text {fric }}:$ Frictional force & $F_{\text {fric }}[\mathrm{N}]$ \\
\hline & $z_{p r e}:$ pre-defined excitation signal & $\begin{array}{l}z_{p r e}[m]=A m p \times \sin (2 \times \pi \times \omega \times t) \\
\text { (Amp (Amplitude) }: 0.1 \mathrm{~m} / \\
\omega \text { (frequency) : variable) }\end{array}$ \\
\hline \multirow{4}{*}{$\begin{array}{l}\text { Simulation } \\
\text { condition }\end{array}$} & $P_{A_{-} \text {pre }}:$ pre-defined pressure of chamber A & $P_{A_{-} p e}\left[N / m^{2}\right]=P_{A_{-f f x}}+P_{A_{-} \text {-rolole }} \times \sin (2 \times \pi \times \omega \times t)$ \\
\hline & $\Delta P:$ pressure difference between chambers $\mathrm{A}$ and $\mathrm{B}$ & $\Delta P\left[N / m^{2}\right]=\frac{\left(m \ddot{z}_{p r e}+c \dot{z}_{p r e}+k z_{p e r}+m g+F_{f i c}\right)}{A}$ \\
\hline & $P_{B_{-} p r e}:$ pre-defined pressure of chamber B & $P_{B_{-} \text {pre }}\left[N / m^{2}\right]=\Delta P+P_{A_{-} \text {pre }}$ \\
\hline & $Q_{A} / Q_{B}:$ Volume flow of chambers A and B & $\begin{array}{l}Q_{A} / Q_{B}\left[m^{3} / s\right]= \\
f\left(z_{p r e}, \dot{z}_{p r}, P_{A_{-p r e}}, P_{B_{-} p r e}, \dot{P}_{A_{-p r} p}, \dot{P}_{B_{-p r e}}\right)\end{array}$ \\
\hline
\end{tabular}

3.2. Natural characteristic of the mass-damper-spring system with two hydraulic servo systems and dynamic characteristic variations according to design variables and geometric factors

The hydraulic servo system can predict not only the leakage, friction, and spring stiffness, but also geometric factor of the hydraulic cylinder and spring. The geometric factor can cause an imbalance. Simulations were conducted for three operating conditions (Table 3) using the design parameters in Table 2.

Table 3. Design parameters simulated in the 2-DoF system.

\begin{tabular}{|c|c|}
\hline Case & Operating condition \\
\hline 1 & $l_{h 1} \neq l_{h 2}$ \\
\hline 2 & $l_{s 1} \neq l_{s 2}$ \\
\hline 3 & $k_{s 1} \neq k_{s 2}$ \\
\hline
\end{tabular}

\section{RESULTS AND DISCUSSION}

\subsection{Natural characteristic of the mass-damper-spring system with one hydraulic servo system}

If additional dampers and springs and springs are not used, system characteristics are determined by the mass and the hydraulic cylinder. The integrated natural frequency is $\omega_{\mathrm{h}, \text { theory }}=22.9504 \mathrm{~Hz}$. We detected a similar natural frequency $\omega_{\mathrm{h}, \text { numerical }}=23 \mathrm{~Hz}$ in a fast Fourier transform (FFT) of the dynamic response. When the hydraulic cylinder volume is low, the natural peak in the dynamic response is weak. When we apply an input signal that equals the natural frequency, the system showed different dynamic behaviors depending on the order of the Taylor series (Table 4). When we calculate the pressure with over a 2nd-order Taylor series, the system does not have a z-directional resonance phenomenon and well follow the red input signal, but the resonance phenomenon happens with a 1st-order Taylor series (Figure 3); therefore the controller must check the pressure 
distribution and high derivative terms in real time for an accurate prediction of the system. Therefore, we used the 3rd-order Taylor series in all simulations.

Table 4. Dynamic response under different Taylor series order.

\begin{tabular}{|c|c|c|}
\hline & 1 st order Taylor series & 2nd order and higher order Taylor series \\
& $P_{i}=f\left(P_{i-1}, \dot{P}_{i-1}\right)$ & $P_{i}=f\left(P_{i-1}, \dot{P}_{i-1}, \ddot{P}_{i-1}, \dddot{P}_{i-1} \ldots\right)$ \\
\hline Dynamic response & Resonance about z-direction & Same response to an input signal \\
\hline
\end{tabular}
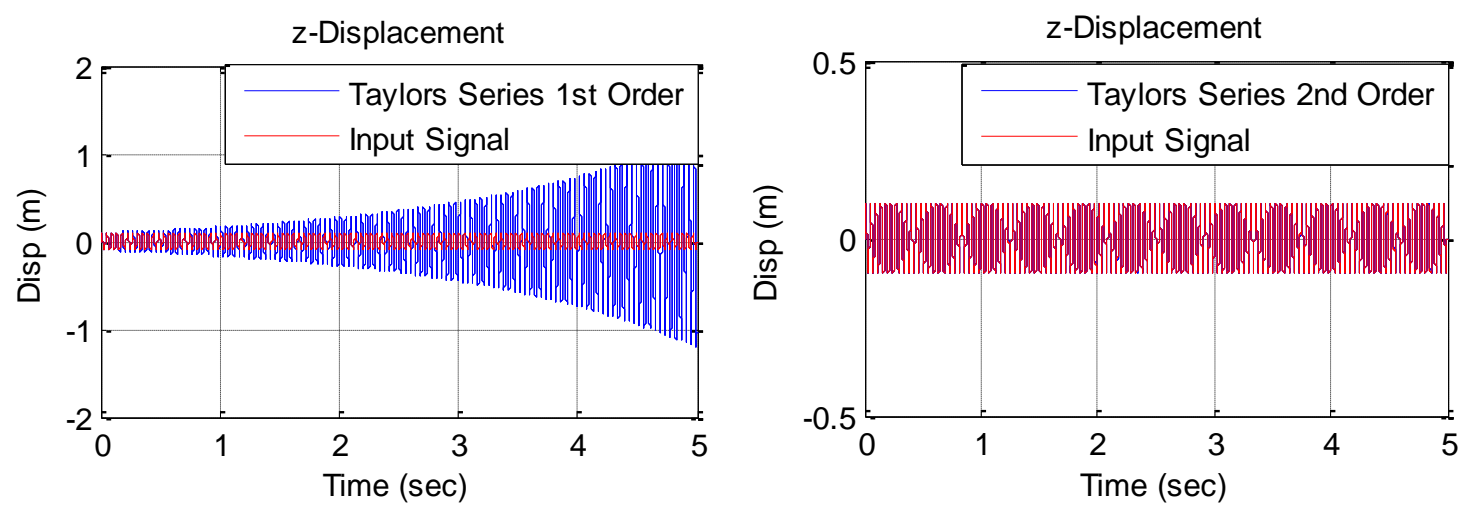

Fig. 3. Dynamic response of the system according to 1st-order and 2nd-order Taylor series.

When the additional spring stiffness was applied, the integrated natural frequency changed. We define an equivalent stiffness model of the hydraulic cylinder with the additional spring stiffness. (equation (7)) [21]. From this point, the additional spring and hydraulic cylinder represent a mechanical and hydraulic part respectively.

$$
\omega_{\text {mechanical }}=\sqrt{\frac{h_{\text {spring }}}{m}} / \omega_{\text {hyd }}=\sqrt{\frac{k_{\text {hyd }}}{m}} / \omega_{\text {int }}=\sqrt{\frac{k_{\text {hyd }}+h_{\text {spring }}}{m}}
$$

The mechanical natural frequency is $10 \mathrm{~Hz}$, so the integrated natural frequency is $25 \mathrm{~Hz}$ from $23.95 \mathrm{~Hz}$ by (Equation (7)). The system does not have a resonance phenomenon by predicting the spring stiffness, while oscillating the integrated natural frequency as explained in previous section. The pressure in the hydraulic cylinder varied according excitation frequency (Figure 4). When the excitation frequency was varied from $1 \mathrm{~Hz}$ to $30 \mathrm{~Hz}$, the pressure variation was lowest at $10 \mathrm{~Hz}$, which is the mechanical natural frequency.

Omitting the spring stiffness greatly affected the pressure variation. In this case, entrance flows $Q_{A}$ and $Q_{B}$ do not consider the spring stiffness, even though the system does include this spring. The system showed a resonance peak and the highest pressure variation at $25 \mathrm{~Hz}$, which is the integrated natural frequency (Figure 4 and 5). These results emphasize that spring information must be included in models of a control system for a mold oscillator.

The dynamic characteristics are also affected by leakage and friction, which act as a flux in the continuity equation, and as an external force in the equation of motion, respectively. We assume that the system does not include these factors in the pre-defined entrance flow. 

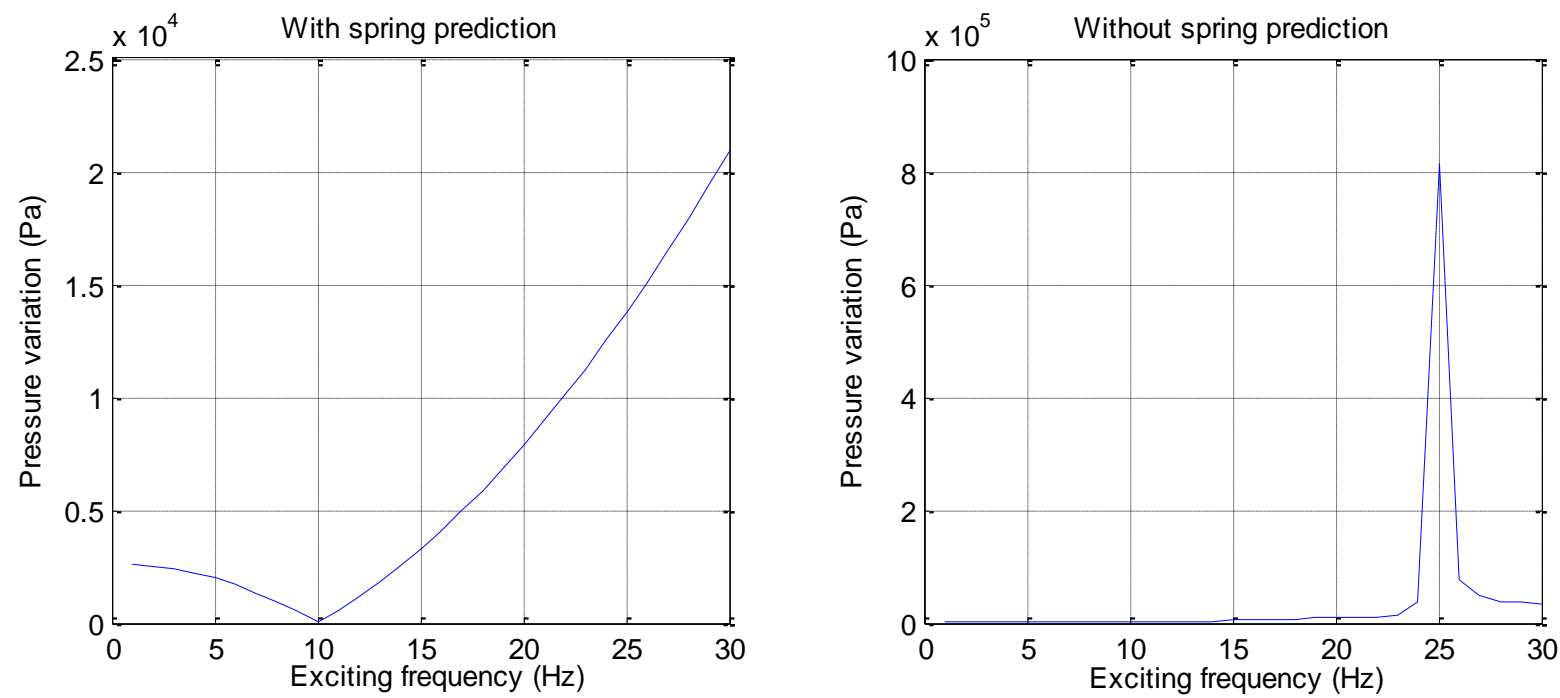

Fig .4. Hydraulic cylinder pressure distribution.

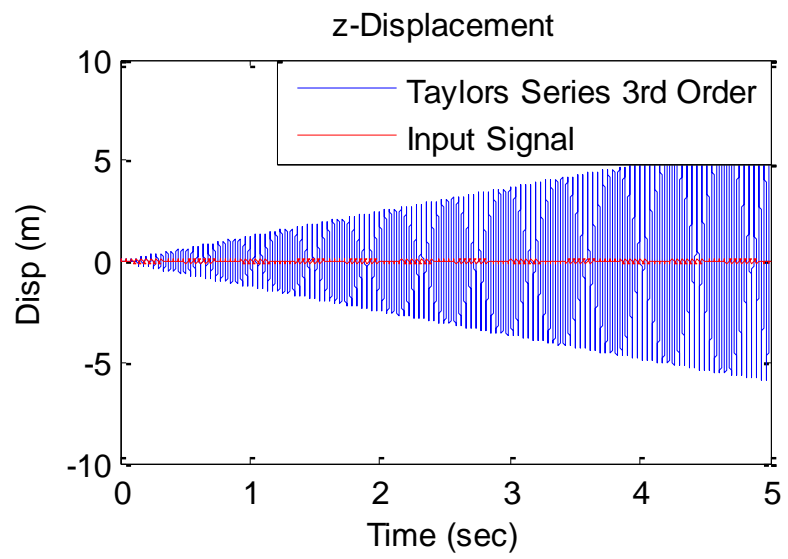

Fig. 5. Resonance phenomenon without the spring prediction, while oscillating the integrated natural frequency $25 \mathrm{~Hz}$.

Friction caused the lowest pressure variation at the integrated natural frequency, because near this frequency frictional force increases as the mass velocity increases. Displacement at the highest and lowest oscillating position deviated from sinusoidal when the direction of velocity changed (Figure 6). This distortion increased as the frictional force increased. Additionally, the excitation frequency and its harmonic term peaks are obvious in the frequency domain.

Leakage varied linearly with the entrance flow, so additional peak occurred; instead, the mass displacement could not follow the input signal. The relationship between pressure variation and excitation frequency was similar to that in Figure 4. The When leakage coefficient increased, the pressure decreased dramatically near the integrated natural frequency (Figure 7). 


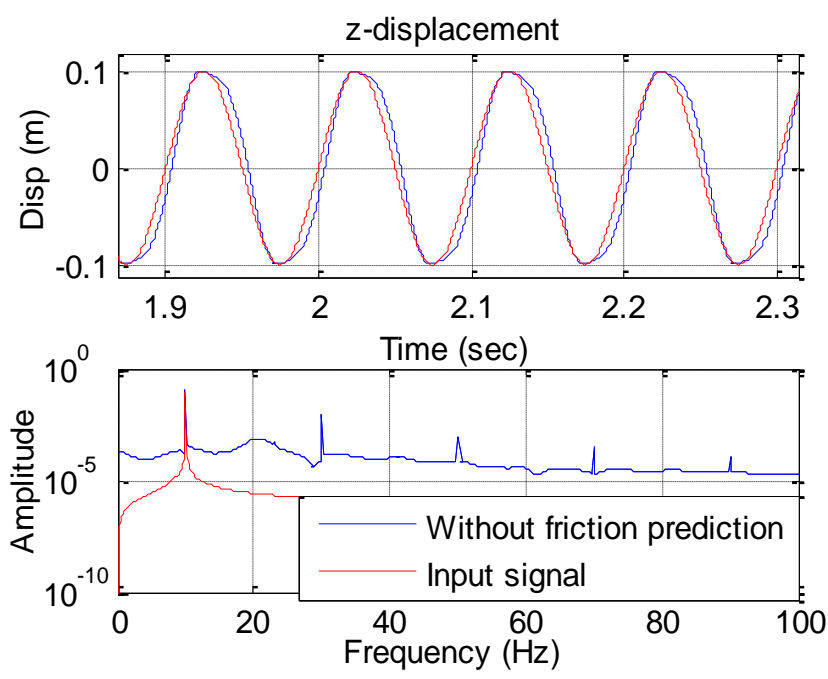

Fig. 6. Dynamic response according to frictional force.
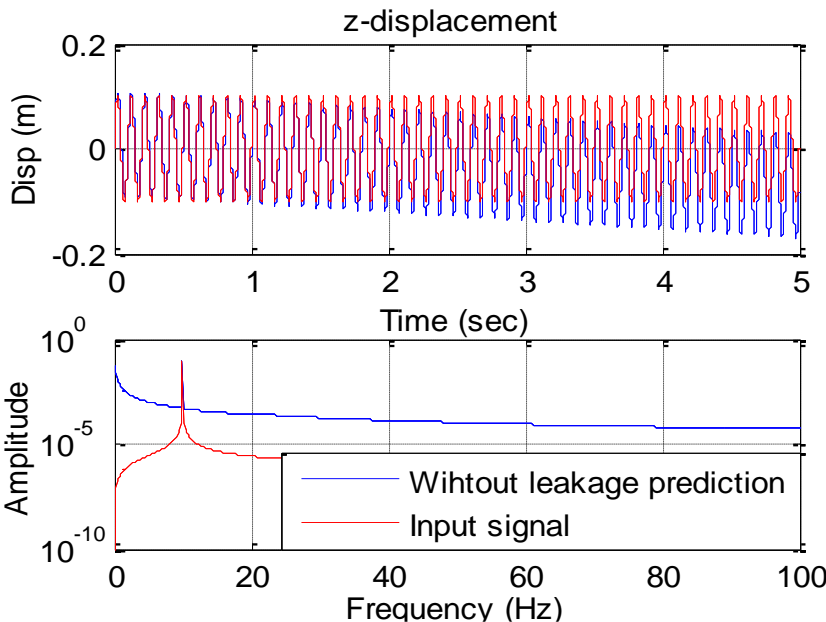

Fig. 7. Dynamic response according to oil-leakage.

4.2. Natural characteristic of the mass-damper-spring system with two hydraulic servo systems according to hydraulic cylinder position

We define a length difference between the left hydraulic cylinder and right hydraulic cylinder $\left(l_{\mathrm{h}, \text { left }}=\mathrm{l}_{\mathrm{h} 1}=1.1 \times\right.$ $\left.1_{\mathrm{h} \text {,original }} ; \mathrm{l}_{\mathrm{h}, \text { right }}=\mathrm{l}_{\mathrm{h} 2}=0.9 \times \mathrm{l}_{\mathrm{h} \text {,original }}\right)$. The spring stiffness is not applied. FFT of the dynamic response revealed that integrated natural frequencies are $32.27 \mathrm{~Hz}$ and $62.6 \mathrm{~Hz}$. The right hydraulic cylinder had much higher pressure than the left cylinder, due to the length difference (Figure 8).

To find a relationship between excitation frequency and natural frequency, the excitation frequency was considered according the integrated natural frequency boundary (Table 5). z-Directional resonance occurred near the 1 st integrated natural frequency, and $\theta$-directional resonance occurred near the 2 nd integrated natural frequency. The $\theta$ resonance oscillates within a limit, but can be considered a resonance because the limit is much bigger than a normal oscillation.

Another observation of interest thing is that the right hydraulic cylinder had higher pressure than the left cylinder when excitation frequency was lower than the 2 nd integrated natural frequency, but the left hydraulic cylinder had higher pressure than the right cylinder when the excitation frequency was higher than the 2nd integrated natural frequency (Figure 9). Also, phase difference and the beat phenomenon occurred; i.e., imbalance happens dramatically, and the system goes out of control. 


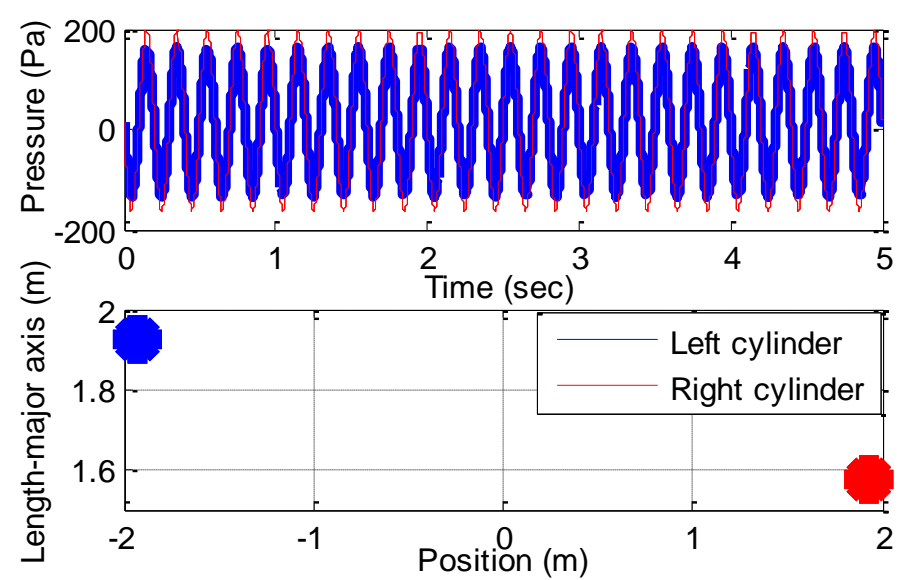

Fig. 8. Pressure distribution in left and right hydraulic cylinders.

Table 5. Oscillating characteristic according to excitation conditions.

\begin{tabular}{|c|c|c|c|c|c|}
\hline & $\omega<1$ st $\omega_{\mathrm{n}, \mathrm{int}}$ & $\omega \approx 1 \mathrm{st} \omega_{\mathrm{n}, \mathrm{int}}$ & $\begin{array}{c}1 \text { st } \omega_{\mathrm{n}, \text { int }}<\omega \\
<2 \mathrm{st} \omega_{\mathrm{n}, \mathrm{int}}\end{array}$ & $\omega \approx 2 \mathrm{nd} \omega_{\mathrm{n}, \mathrm{int}}$ & $\omega>2$ nd $\omega_{n, \text { int }}$ \\
\hline Displacement & $\begin{array}{c}\text { Similar } \\
\text { input signal }\end{array}$ & $\begin{array}{c}\text { Resonance } \\
\text { or beat about } \\
\text { z-displacement }\end{array}$ & $\begin{array}{l}\text { Input signal } \\
\text { and local beat }\end{array}$ & $\begin{array}{c}\text { Resonance } \\
\text { or beat about } \\
\theta \text {-displacement }\end{array}$ & $\begin{array}{l}\text { Input signal } \\
\text { and local beat }\end{array}$ \\
\hline Pressure & Right $>$ Left & Right > Left & Right > Left & Right > Left & Left > Right \\
\hline
\end{tabular}

Next, we considered an influence of the additional spring stiffness on the dynamic characteristics. The spring stiffness is not included in the pressure calculation, even though the spring stiffness. Generally, the distribution of mean pressure the left and right hydraulic cylinder (Figure 10) was not different from the previous result (Figure 4). Pressure variation was greatest near the integrated 1st natural frequency $(33 \mathrm{~Hz})$, and lowest near the 1st mechanical natural frequency $(7 \mathrm{~Hz})$. Additionally, a local beat phenomenon in the z-direction occurred near the 2 nd mechanical natural frequency. These results indicate that operating condition can only include the 1 st mechanical natural frequency.
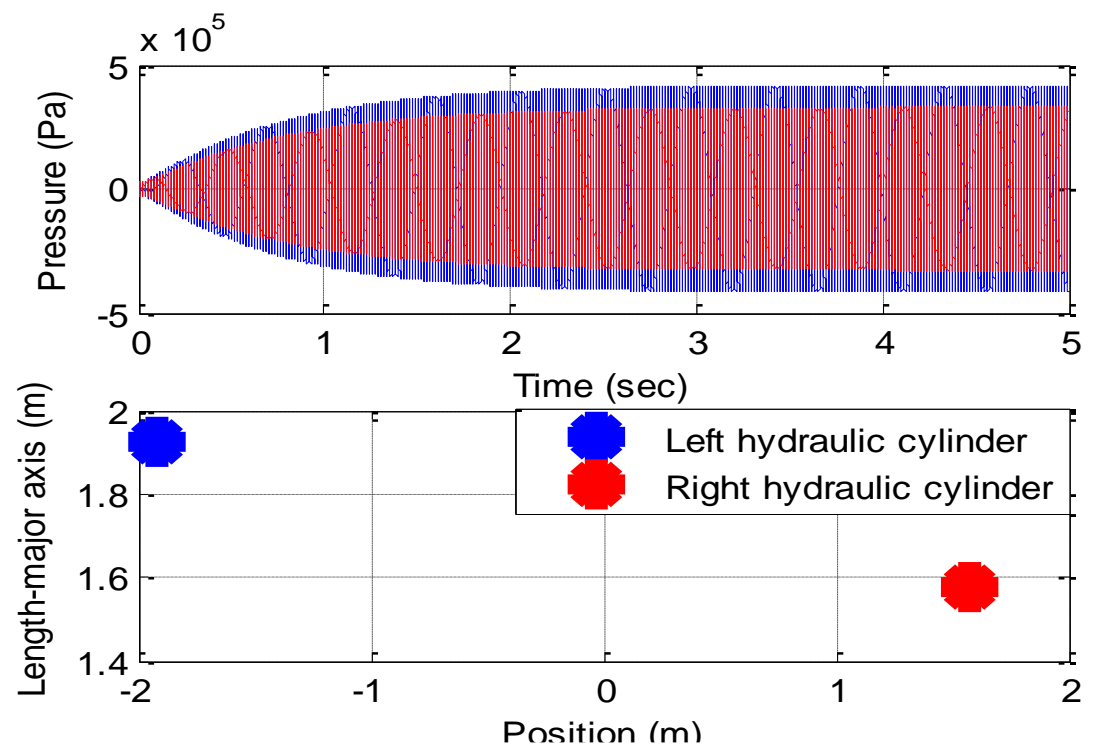

Fig. 9. Pressure distribution of the left and right hydraulic cylinder when excitation frequency is near the 2nd integrated natural frequency. 


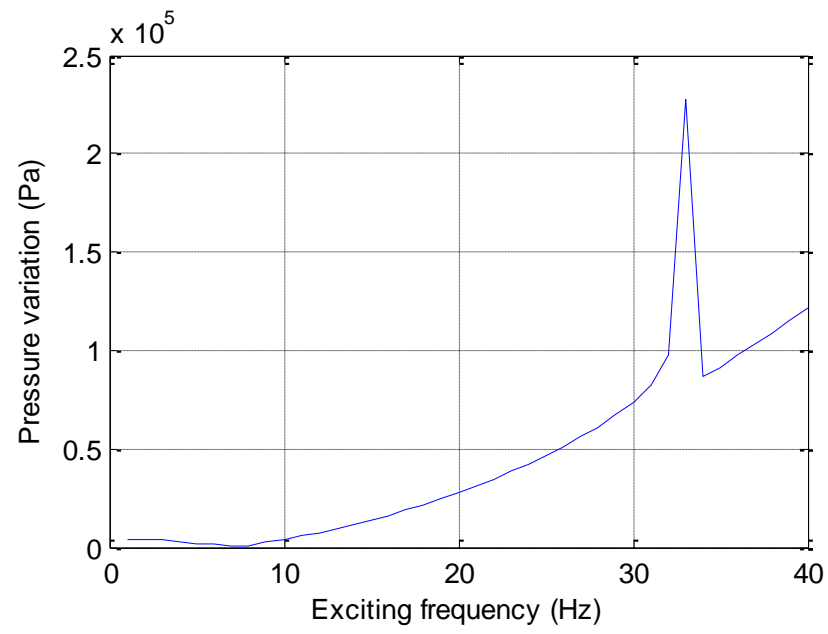

Fig. 10. Pressure variation of the left and right hydraulic cylinders according to excitation frequency when 1st $\omega_{\mathrm{n}, \text { mech }}=7 \mathrm{~Hz}$ and $1 \mathrm{st} \omega_{\mathrm{n}, \text { int }}=33 \mathrm{~Hz}$.

\subsection{Natural characteristic of the mass-damper-spring system with two hydraulic servo systems according} the spring imbalance

In the system with two hydraulic servo systems, the spring stiffness changes not only the mechanical natural frequency, but also the integrated natural frequency. We established at system that had mechanical natural frequencies $2.18 \mathrm{~Hz}$ and $10.18 \mathrm{~Hz}$ with different distances between the left spring and right spring (ls, left = ls1 $=2.5 \times 1 \mathrm{~s}$, original $/ \mathrm{ls}$, right $=1 \mathrm{~s} 2=0.5 \times \mathrm{ls}$, original). Pressure variation was lowest at the 1 st mechanical natural frequency, a local beating phenomenon occurred at the 2nd mechanical natural frequency, z-directional resonance occurred at the 1st integrated natural frequency $(\sim 33 \mathrm{~Hz})$, and increasing $\theta$ displacement occurred at the 2 nd integrated natural frequency $(\sim 125 \mathrm{~Hz})$. Because in this simulation considers the left spring length to the center of gravity is longer than the right spring length to the center of gravity, the 2nd integrated natural frequency due to the spring imbalance causes an extreme imbalance between left and right displacements of the mold (Figure 11); a similar phenomenon was observed in Section 4.2.

The excitation conditions affected the oscillation characteristics (Table 6). When the excitation frequency was higher than the 2nd mechanical natural frequency, the displacement of the left and right positions increased, even though the displacement of the center followed the input signal well.

Table 6. Oscillating characteristic according excitation conditions.

\begin{tabular}{|c|c|c|c|c|c|}
\hline & $\omega<1$ st $\omega_{\mathrm{n}, \text { mech }}$ & $\begin{array}{l}1 \text { st } \omega_{\mathrm{n}, \text { mech }}<\omega \\
<2 \text { nd } \omega_{\mathrm{n}, \text { mech }}\end{array}$ & $\begin{array}{c}2 \text { nd } \omega_{\mathrm{n}, \mathrm{mech}}<\omega \\
\quad<1 \mathrm{st} \omega_{\mathrm{n}, \mathrm{int}}\end{array}$ & $\begin{array}{c}1 \text { st } \omega_{\mathrm{n}, \text { int }} \\
<\omega<2 \text { nd } \omega_{\mathrm{n}, \text { int }}\end{array}$ & $\omega>2 \mathrm{nd} \omega_{\mathrm{n}, \mathrm{int}}$ \\
\hline Displacement & $\begin{array}{c}\text { Similar } \\
\text { input signal }\end{array}$ & $\begin{array}{c}\text { Similar } \\
\text { input signal }\end{array}$ & $\begin{array}{c}\text { Similar } \\
\text { input signal } \\
\text { (increasing gap } \\
\text { between } \\
\text { the left (up) } \\
\text { and right } \\
\text { (down) } \\
\text { cylinder) }\end{array}$ & $\begin{array}{c}\text { Similar } \\
\text { input signal } \\
\text { (more } \\
\text { increasing gap } \\
\text { between the } \\
\text { left (up) } \\
\text { and right } \\
\text { (down) } \\
\text { cylinder) }\end{array}$ & $\begin{array}{c}\text { Input signal } \\
\text { and divergence } \\
\text { (more increasing gap } \\
\text { between the left (up) } \\
\text { and right (down) } \\
\text { cylinder) }\end{array}$ \\
\hline Pressure & Left $>$ Right & Right $>$ Left & Right $>$ Left & Right $>$ Left & Left > Right \\
\hline
\end{tabular}

The hydraulic cylinder imbalance causes a phase difference between the left and right, and the spring imbalance changes the center of oscillation between the left and right, when excitation at the 2nd integrated frequency is applied. (Figure 12) Due to the lack of paper length, we don't show a result about the length imbalance of the 
spring. But the stiffness imbalance can correspond the length imbalance of the spring. For instance, a left spring stiffer than the right is equivalent to the left spring being farther from the center than the right is.

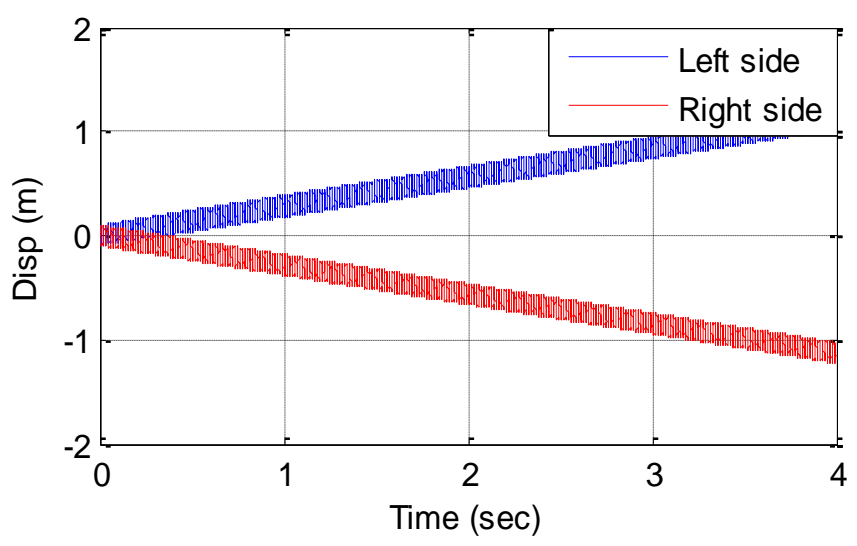

Fig. 11. Displacement of the left-right side of the mold with oscillating 2nd integrated natural frequency.
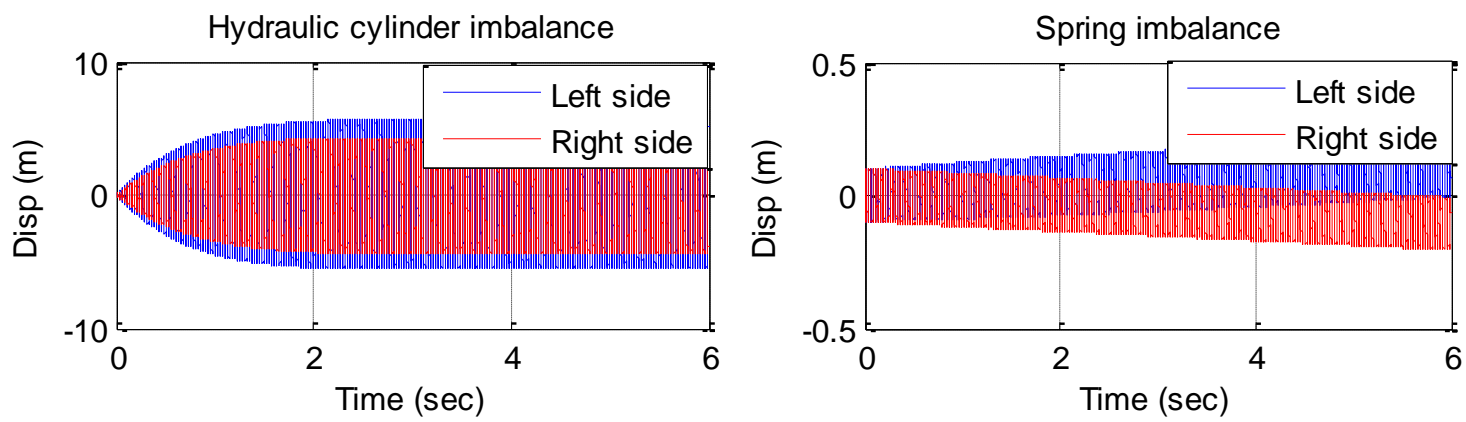

Fig. 12. Comparison between the hydraulic cylinder (Up) and spring imbalances (Down).

\subsection{Application to the mold oscillation in real operation}

We use the model to investigate experimental data from the mold oscillator from the real operation [22], in which a sine sweeping input signal was applied at $2 \leq \mathrm{S} \leq 10 \mathrm{~mm}$ and $1 \leq \mathrm{f} \leq 7 \mathrm{~Hz}$, and displacement and pressure of the hydraulic cylinder were acquired (Figure 13). Figure 13 is one of case; a sweeping oscillation with $\mathrm{S}=2 \mathrm{~mm}$ and $1 \leq \mathrm{f} \leq 7 \mathrm{~Hz}$. The left hydraulic cylinder was always displaced less than was the right cylinder. This means that the mold oscillator does not oscillate horizontally. The non-horizontal oscillation is no change, even though excitation frequency changed. This means that the entrance flow of hydraulic oil differs between the left and right cylinders. The physical phenomenon were:

- No integrated natural frequency exists between $1 \sim 7 \mathrm{~Hz}$ (No pressure up rapidly);

- The 1st mechanical natural frequency is $\sim 3 \mathrm{~Hz}$ (The lowest pressure);

- The 2nd mechanical natural frequency is $\sim 5 \mathrm{~Hz}$ (Beat phenomenon);

- Friction force acts primarily over $3 \mathrm{~Hz}$ (displacement distortion, excitation and harmonic peak frequency);

- Pressure variation of the left hydraulic cylinder is higher than the right hydraulic cylinder at $1 / 2 / 4 / 5 \mathrm{~Hz}$. But the right is higher than the left at the other oscillating frequency;

- Displacement variation between the left and right cylinder increases dramatically at $6 \mathrm{~Hz}$ when S> $6 \mathrm{~mm} ; 6 \mathrm{~Hz}$ is the 2nd mechanical natural frequency (Figure 14);

- Additional peak frequencies happen at 49/48/47/46/45/44/43 Hz according to $1 / 2 / 3 / 4 / 5 / 6 / 7 \mathrm{~Hz}$ excitation frequencies: the integrated natural frequency, the line volume near the chamber increases (Figure 15).

The final observation is that the integrated natural frequency decreases as the excitation frequency increases (i.e., as spring stiffness or hydraulic stiffness decrease, or mass increases). Additionally, displacement decreases as excitation frequency increases; this phenomenon is related linearly to the leakage problem as explained in (Figure 7). Therefore, the variation in integrated natural frequency and in pressure drop come from the line volume that is entering to the hydraulic cylinder, and leakage problem respectively.

By using the FE multi-body dynamics model to validate the results, we could match the mechanical natural frequency by mode analysis that shows $2.499 \mathrm{~Hz}, 5.446 \mathrm{~Hz}$ natural mode equally. 


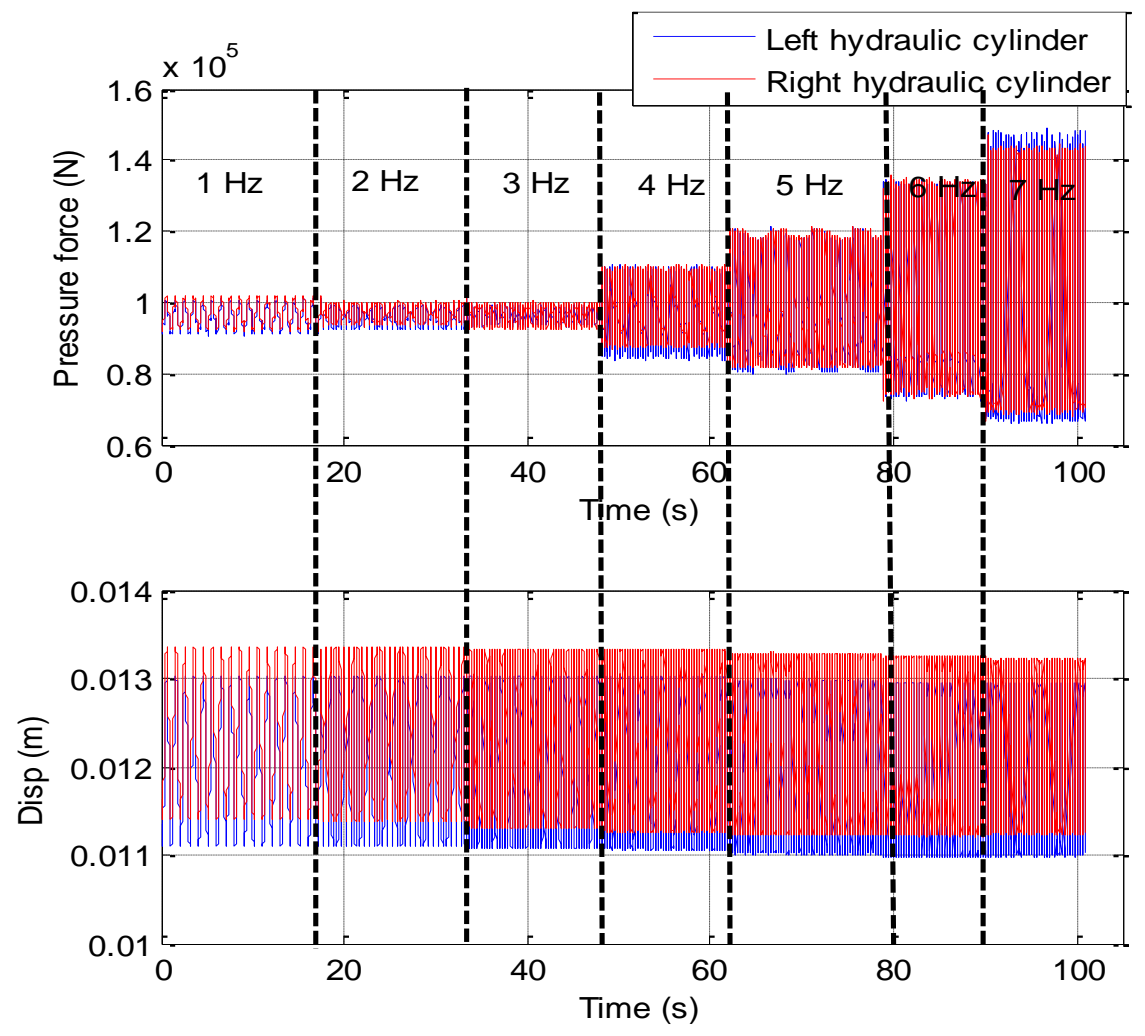

Fig. 13. Time history of displacement and pressure of hydraulic cylinder in the mold oscillator.

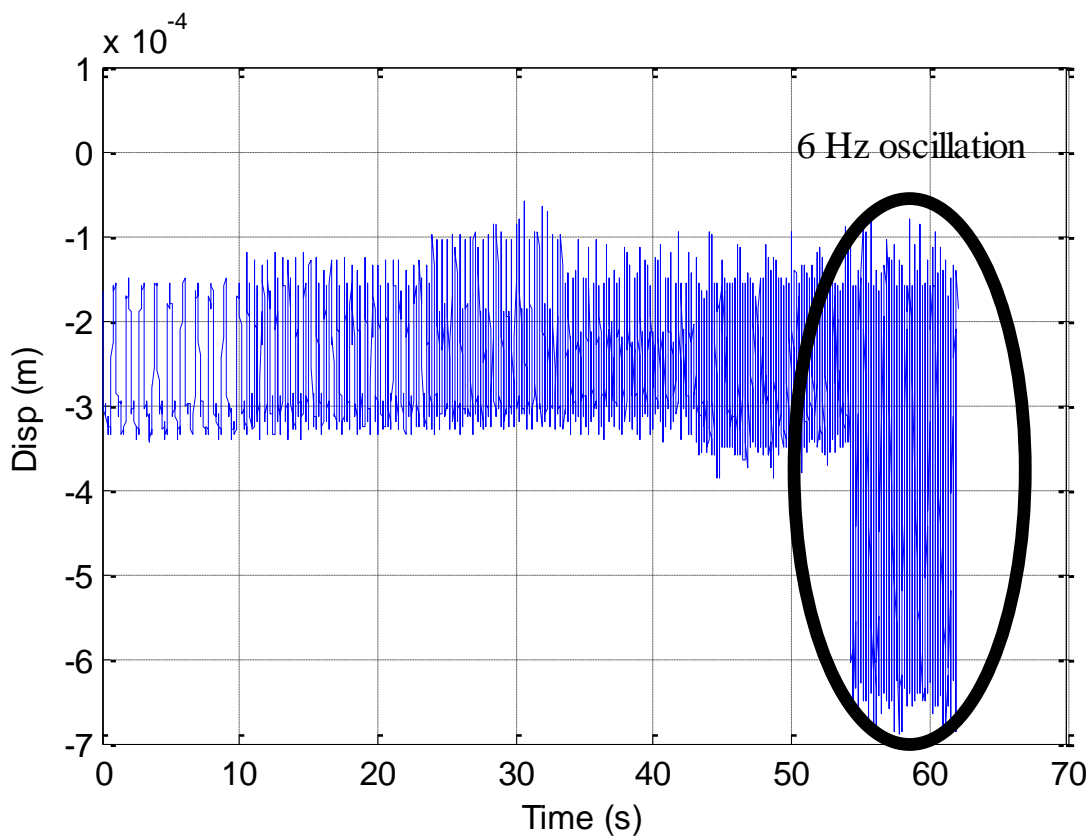

Fig. 14. Displacement difference between the left and right cylinder with 6-mm sweeping sine. 


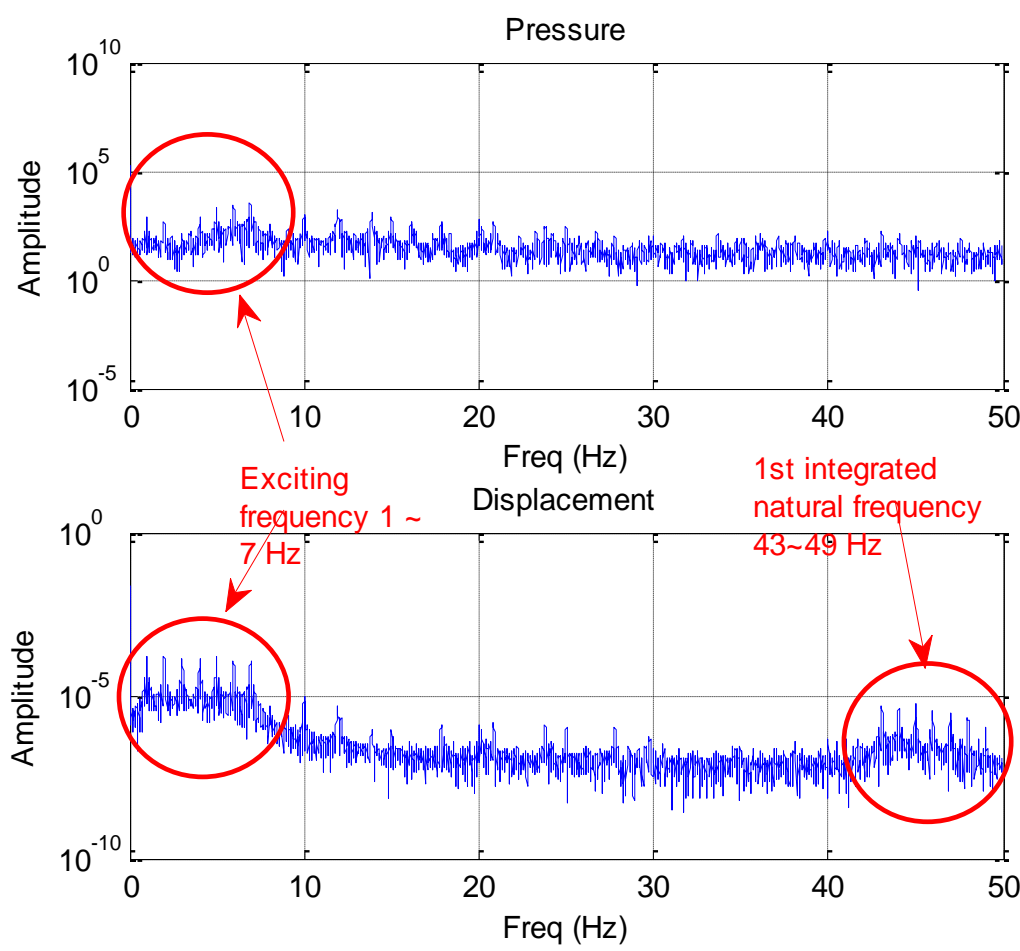

Fig. 15. Frequency analysis of displacement and pressure of hydraulic cylinder in the mold oscillator.

\section{CONCLUSION}

We used a mass-damper-spring model to investigate a mold oscillating system that uses a hydraulic servo system. We reestablish basic mechanisms of the hydraulic servos system, and expand the model that considers geometrical factors including length and stiffness.

Analysis of a mass-damper-spring system with one hydraulic servo system shows the importance of predicting the entrance flow and relationship between external factors. A mass-damper-spring system with two hydraulic servo systems gives four natural frequencies: the 1 st $\& 2$ nd mechanical natural frequency and the 1 st $\& 2$ nd integrated natural frequency.

The 1st mechanical natural frequency is classified as safe region, because it can give the lowest pressure distribution to oscillate same stroke. However, other frequencies cause imbalance between the left and right systems, beating, or resonance phenomenon.

To operate the mold oscillator efficiently, these guidelines should be followed based on the simulation result:

- Check the entrance flow in the left and right hydraulic cylinder;

- Check the point of inflection of the pressure and displacement;

- Simulate an operation with the entrance flow;

- Check torsion of the mold oscillator;

- Based on a simulation result and torsional displacement result, modify design variables as needed.

\section{ACKNOWLEDGEMENTS}

This work was supported by the Korea Institute for Advancement of Technology (KIAT) grant funded by the Korea Government - Ministry of Trade Industry and Energy (MOTIE). (2015 Establishment of GEM , No. H2001-13-1001). The authors thanks to Pohang Institute of Metal Industry Advancement and Department of Mechanical Engineering and Graduate school of Engineering Mastership, POSTECH for their laboratory facilities, including MATLAB software. 


\section{REFERENCES}

[1] Bonchis, Adrian, Corke, P.I., Rye, D.C., Ha, Q.P., Variable structure methods in hydraulic servo systems control, Automatica, vol. 37, no. 4, 2001, p. 589-595.

[2] Yousefi, H., On modelling, system identification and control of servo-systems with a flexible load, Ph.d thesis, Acta Universitatis Lappeenrantaensis, 2007.

[3] Rydberg, K.E., Hydraulic servo systems, Fluid and Mechanical Engineering Systems. Linköping University, 2008.

[4] Jeongju, C., robust position control of electro-hydrostatic actuator systems with radial basis function neural networks, Journal of Advanced Mechanical Design, Systems, and Manufacturing, vol. 7, no. 2, 2013, p. 257-267. [5] Han, M.K., Jeongju, C., Robust tracking control for hydraulic actuator using backstepping sliding mode control, Journal of Advanced Mechanical Design, Systems, and Manufacturing, vol. 8, no. 2, 2014, p. JAMDSM0011-JAMDSM0011.

[6] Li, F.K., Ma, C.L., Yu, J., Dynamic modeling and tracking control simulation for large electro-hydraulic servo system, Applied Mechanics and Materials, vol. 416, 2013, p. 811-816.

[7] Hiremath, S.S., Modeling and simulation of fluid structure interaction in jet pipe electrohydraulic servovalve, International Journal of Recent advances in Mechanical Engineering, vol. 2, no. 4, 2013, p. 1-14.

[8] Zhiyong, W, Herong, J., Dezhong, Z., Hydraulic roll-bending predictive control based on time series prediction error compensation, Proceedings of the Institution of Mechanical Engineers, Part B: Journal of Engineering Manufacture, vol. 226, no. 9, 2012, p. 1500-1505.

[9] Edge, K.A., Darling, J, Cylinder pressure transients in oil hydraulic pumps with sliding plate valves, proceedings of the institution of mechanical engineers, Part B: Journal of Engineering Manufacture, vol. 200, no. 1, 1986, p. 45-54.

[10] Jae-Cheon, L., Yong-Seung, C., A Study on the estimation of effective bulk modulus of hydraulic oil with pressure variation, Transactions of the Korean Society of Automotive Engineers, vol. 11, no. 1, 2003, p. 179184.

[11] Ill-Yeong, L., Dandan, Sun, Effects of cylinder shell elasticity on effective bulk modulus of oil in automotive hydraulic dampers, Transactions of the Korean Society of Automotive Engineers, vol. 12, no. 5, 2004, p. 187-197.

[12] Edge, K.A., Figueredo, K.R.A., An adaptively controlled electrohydraulic servo-mechanism: part 2: implementation, Proceedings of the Institution of Mechanical Engineers, Part B: Journal of Engineering Manufacture, vol. 201, no. 3, 1987, p. 181-189.

[13] Choux, M., Hovland, G., Design of a hydraulic servo system for robotic manipulation, In: 5th FPNI Ph. D Symposium. Krakow, Poland, 2008, p. 1-5.

[14] Maneetham, D., Nitin, A., Modeling, simulation and control of high speed nonlinear hydraulic servo system, Journal of Automation Mobile Robotics and Intelligent Systems, vol. 4, 2010, p. 94-103.

[15] Jelali, M., Andreas, K., Hydraulic servo-systems: modelling, identification and control, Berlin, Springer Science \& Business Media, 2012.

[16] Laurenson, I., The design of self-centring seal-lesshydraulic pistons, Proceedings of the Institution of Mechanical Engineers, Part B: Journal of Engineering Manufacture, vol. 199, no. 1, 1985, p. 59-65.

[17] Shin, H.G., Choi, W., Kang, S., Kim, S., Park, J., and Thomas, B. G., Effect of mold oscillation on powder consumption and hook formation in ultra-low carbon steel slabs, Iron and Steel Technology, vol. 2, no. 9, 2005, p. 56.

[18] Ramirez, L., Pavel, E., Peter, D.L, Mills, C.K., Explicit modelling of slag infiltration and shell formation during mould oscillation in continuous casting, ISIJ International, vol. 50, no. 3, 2010, p. 425-434.

[19] Wendelstorf, J., Sensitivity analysis of a thermo mechanical process model for shell formation in continuous casting, In: STEELSIM 2001, METEC InSteel Con, Düsseldorf, Germany, 2011.

[20] Junhong, Y., Andrew, P., Yong, X., Dynamic friction modelling without drift and its application in the simulation of a valve controlled hydraulic cylinder system, Journal of Advanced Mechanical Design, Systems, and Manufacturing, vol. 8, no. 6, 2014, p. JAMDSM0075-JAMDSM0075.

[21] Medhat, B.K.L, Interactive analysis of closed loop electro-hydraulic control systems, In: 13th International Conference on AEROSPACE SCIENCES \& AVIATION TECHNOLOGY (ASAT), Cairo, Egypt, 2009.

[22] Kang, G.P, Sungjin, L., Apparatus for mould oscillation and mould equipment for continuous casting using the same, South Korea Patent 2014, 1020140005429. 